\title{
CHANGES OF OUTFLOW AND SHALLOW GROUNDWATER LEVEL IN SMALL MOUNTAINOUS BASINS IMMEDIATELY AFTER THE 2011 EARTHQUAKE OFF THE PACIFIC COAST OF TÖHOKU
}

\author{
K. TAMAI \\ Forestry \& Forest Products Research Institute, Japan
}

\begin{abstract}
An increase of outflow of 1.70-4.66 mm was observed in five mountain small basins within areas that sustained a tremor of lower 6 on the Japanese intensity scale in Ibaraki during the 7-8 days immediately after the 2011 earthquake off the Pacific coast of Tōhoku. The groundwater level dropped as much as about $1 \mathrm{~m}$ in 8 days after the earthquake at a well in one of these watersheds. Comparison of the relation between outflow and groundwater level in this watershed for one year before and after the earthquake suggests that the earthquake has encouraged outflow of water of underground origin. However, the flow increment immediately after the earthquake was not so great. Computational analysis results indicate that the outflow might have been compensated by decline in a groundwater level of about $1.5 \%$ of the area of the basin area, at most. Accordingly, the decline in the groundwater level is regarded as a phenomenon occurring in an extremely limited area within the watershed.
\end{abstract}

Keywords: Aftermath of the 2011 Töhoku earthquake and tsunami, Head water area

\section{INTRODUCTION}

It has been reported broadly that a great earthquake might trigger an increase in outflow or a decline in the groundwater level. For example, Rojstaczer et al. [1] reported a change in river flow after the earthquake that occurred in California, in 1989, as the consequence of an enhanced coefficient of permeability. Regarding decline in groundwater level and much spring water observed in a northern area of Awaji-shima island after the Southern Hyogo Prefecture Earthquake in 1995 in Japan, the coefficient of permeability was variously reported as enhanced by five times or more (Tokunaga [2]) and by about seven times (Sato et al. [3]).

The Forestry and Forest Products Research Institute of Japan has been conducting successive monitoring of outflow at the small mountain basins of the Hitachi Ota site, the Katsura site and the Tsukuba site, all in Ibaraki Prefecture, Japan. Tsuboyama et al. [4] summarized enhanced outflow observed at all these sites immediately after the 2011 earthquake off the Pacific coast of Tōhoku. We compare the 'groundwater level - outflow' relation before and after the earthquake at both Katsura and Tsukuba sites under monitoring of groundwater level and report cases in the small mountain basins in areas that sustained earthquake tremors of lower 6 on the Japanese intensity scale in this study. 'Tremor' is estimated between 1 and 7 by the Japan Meteorological Agency with respect to the shape of a seismic wave. An earthquake with a tremor of less than 6 causes damages such as toppling of unfixed heavy furniture and distortion of doors.

\section{OBSERVATION WATERSHEDS AND PROCEDURE}

The aftermath of the 2011 Tōhoku earthquake and tsunami was triggered by the 2011 earthquake off the Pacific coast of Tōhoku that occurred at 2:46 P.M. on 11 March 2011. A tremor of lower 6 on the Japanese intensity scale was recorded by this earthquake in Shirosatomachi, Higashi Ibaraki County, where the Katsura site $\left(140^{\circ} 31^{\prime}\right.$ east longitude, $36^{\circ} 53^{\prime}$ 


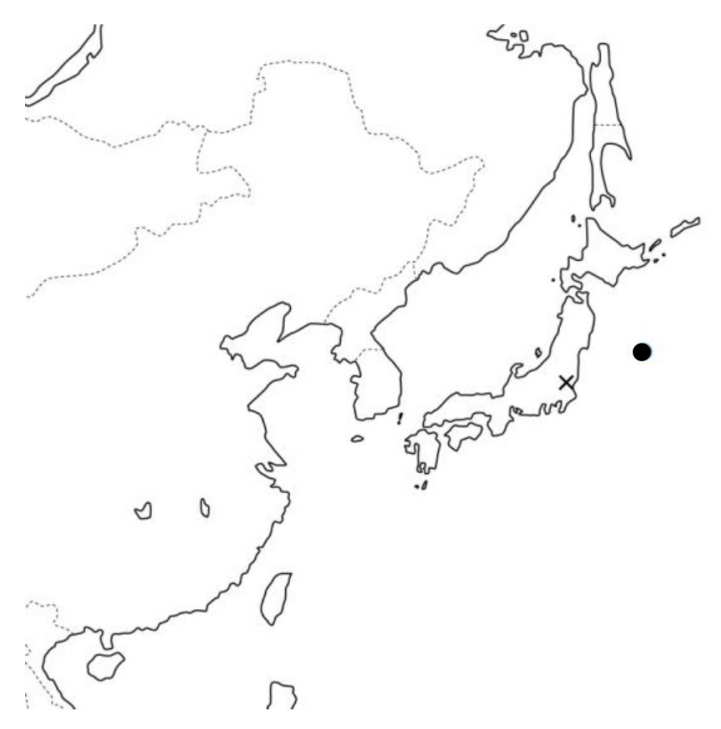

Figure 1: Locations of the observation sites area Black dot, epicentre $\left(142^{\circ} 52^{\prime}\right.$ east longitude, $38^{\circ} 6^{\prime}$ north latitude). Cross, observation sites area $\left(140^{\circ} 10-31^{\prime}\right.$ east longitude, $36^{\circ}$ 10-53' north latitude).

north latitude) is located, and in Ishioka city, where the Tsukuba site $\left(140^{\circ} 10^{\prime}\right.$ east longitude, $36^{\circ} 10^{\prime}$ north latitude) is located (Fig. 1). There was no snow coverage observed at the time of the earthquake at either site, and no snowslide into creeks.

\subsection{Katsura site}

The Katsura site is located along the branch of the Koutogawa River, which has a total watershed of about 59.9 ha, including a watershed of about 2.3 ha in its upper reaches (Fig. 2). The altitudes of the whole and upper watersheds are, respectively, 180-302 $\mathrm{m}$ and 212-272 $\mathrm{m}$. The Kanto loam formation is deposited thickly on shale and chart of the Mesozoic-Paleozoic layers (Onuki et al. [5]). A flow gaging weir was provided at the terminal of the whole and upper watersheds. The outflow was monitored at an interval of $10 \mathrm{~min}$ using a pressure water level gauge (DL/N70; STS AG, Switzerland). Rainfall was measured in the central part of the whole watershed. In addition, the groundwater level was measured in a well in the upper watershed with a depth of $6.0 \mathrm{~m}$ using a pressure water level gauge (HIT-MW; Sensez Corp.) at an interval of 20 min. A drilling survey at the time of digging the well revealed lithology of a surface soil layer down to $4.7 \mathrm{~m}$ deep and a moderately weathered layer comprising clay silt and soil with pebbles thereunder at depths greater than $4.7 \mathrm{~m}$.

\subsection{Tsukuba site}

The Tsukuba site is a watershed of about 3.8 ha along a branch of the Koisegawa River, at an altitude of 290-390 m (Fig. 3). The lithology is mostly biotite gneiss with granite dikes observed locally, covered by a thick Kanto loam formation (Onuki et al. [6]). Outflow was 


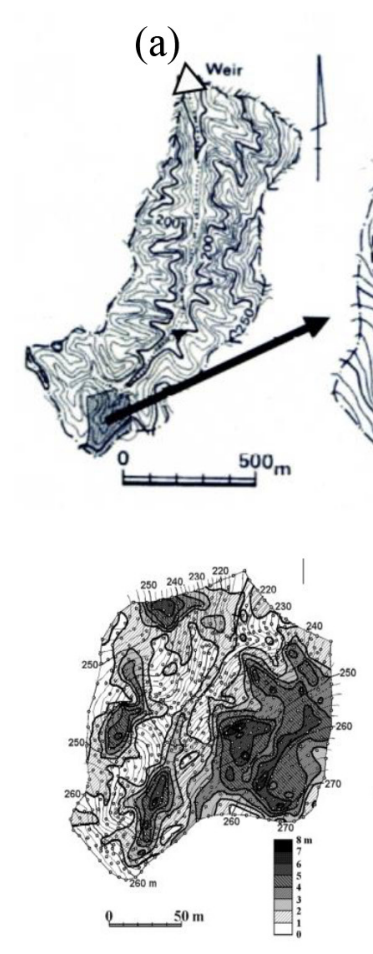

(c)
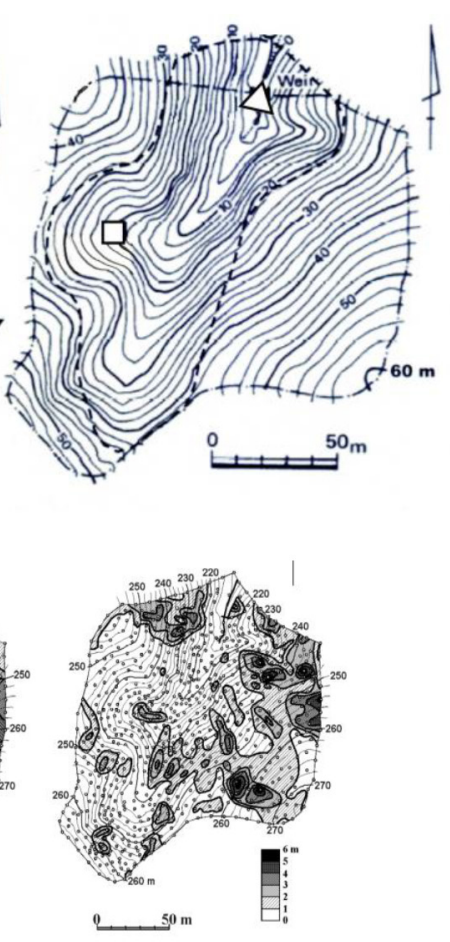

(d)

(b)

Figure 2: Topographic map of the Katsura test site: (a) whole watershed, (b) upper watershed, $\triangle$, outflow observation point; $\square$, groundwater level observation point; (c) distribution of surface soil thickness [5]; (d) distribution of weathered layer thickness [5].

measured at a flow gaging weir placed at the terminal of the watershed (BO) at an interval of 5 min using a pressure water level gauge (DL/N70). Outflow was also monitored at two flow gaging weirs placed in two spring water sources in the upper reaches $(\mathrm{BB}, \mathrm{BC})$ at an interval of 5 min using a pressure water level gauge (DL/N70). The basin areas at $\mathrm{BB}$ and $\mathrm{BC}$ determined by the earth surface topography were 0.96 and 0.63 ha, respectively. Furthermore, manual measurement of the groundwater level was conducted using a measuring scale with a buzzer about once per month, at wells drilled in two places on a slope right above the flow gaging weir at BB with respective depths of $10 \mathrm{~m}(\mathrm{G} 3)$ and $15 \mathrm{~m}$ (G4). The lithology of G3 comprises a loam surface soil layer to a depth of $3.7 \mathrm{~m}$, a weathered layer at 3.7-7.0 m deep, and a gneiss base ground layer thereunder deeper than $7.0 \mathrm{~m}$, whereas that of G4 comprises a surface soil layer to $2.8 \mathrm{~m}$ depth, a weathered layer at 2.8-14.3 $\mathrm{m}$ depth and a base ground layer thereunder at deeper than $14.3 \mathrm{~m}$. Kabeya et al. [7] reported that the peak of outflow enhanced by rainfall appears indistinctly several days after the rainfall as an outflow characteristic from a spring water source $\mathrm{BB}$, and argues that a peak outflow is built up mainly of subsurface flows or underground streams. Noguchi et al. [8] reported that outflow from BB includes little direct outflow composition 


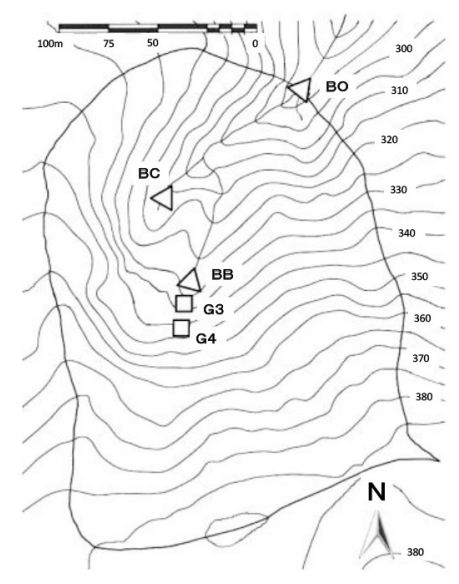

(a)

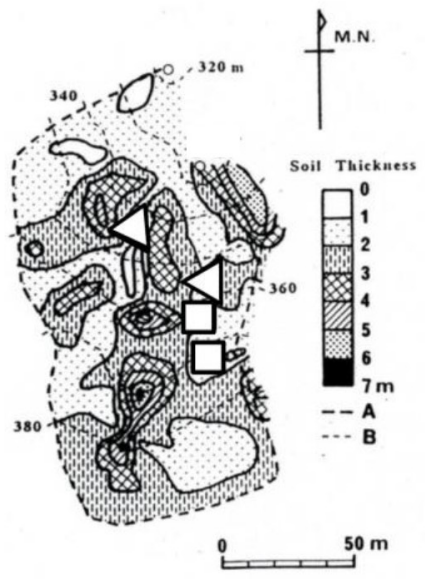

(b)

Figure 3: Topographic map of the Tsukuba site: (a) topographic map of watersheds;

(b) thickness distribution of surface soil layer at upstream BB and BC basins [6];

$\triangle$, outflow observation point; $\square$, groundwater level observation point.

based on the fluctuation of outflow from $\mathrm{BB}$ and $\mathrm{BC}$ at the time of a certain rainfall event. They show the groundwater level at the neighbourhood of the area of a rainfall versus outflow. The observed hysteresis is regarded as resulting from direct outflow at $\mathrm{BC}$, but no hysteresis at BB.

\section{OBSERVATION RESULTS}

\subsection{Increase in outflow and decline in groundwater level at the Katsura site}

Figure 4 portrays the fluctuation of outflow from the upper watershed, the groundwater level of the well in the upper watershed and rainfall for about one year before and after 11 March 2011 when the earthquake occurred. Arrows indicate the timing of the earthquake occurrence. Increase in outflow immediately after the earthquake was too small compared with the increase in those by rainfall to be clearly distinguishable in this figure, although the decline in groundwater level can be recognized distinctly.

Figure 5 provides a magnified view of the earlier figure from 7 March to 27 March, before and after 11 March 2011 when the earthquake occurred, also including outflow from the whole watershed. The arrows show the timing of earthquake occurrence. Outflow started to increase immediately after the earthquake occurrence, and then dropped to the level of outflow before earthquake occurrence on 17 or 18 March. Sharp peaks were observed at the time of outflow increase by rainfall on 7 March and 21-23 March, although the peak at the time of outflow increase immediately after the earthquake on 11 March was blunted, similar to the increase pattern of flow rate by base flow compositions during rainfall.

Broken lines in Figs. 5a and 5b show the outflow at the time of earthquake occurrence. The flow increment defined by an excess outflow over this was $35.9 \mathrm{~m}^{3}$ and $1,018.0 \mathrm{~m}^{3}$, respectively, of the whole watersheds and the upper watersheds. The groundwater level also started to drop rapidly immediately after the earthquake from the surface soil layer to the weathered layer. The water level decline by 18 March was about $1 \mathrm{~m}$. 


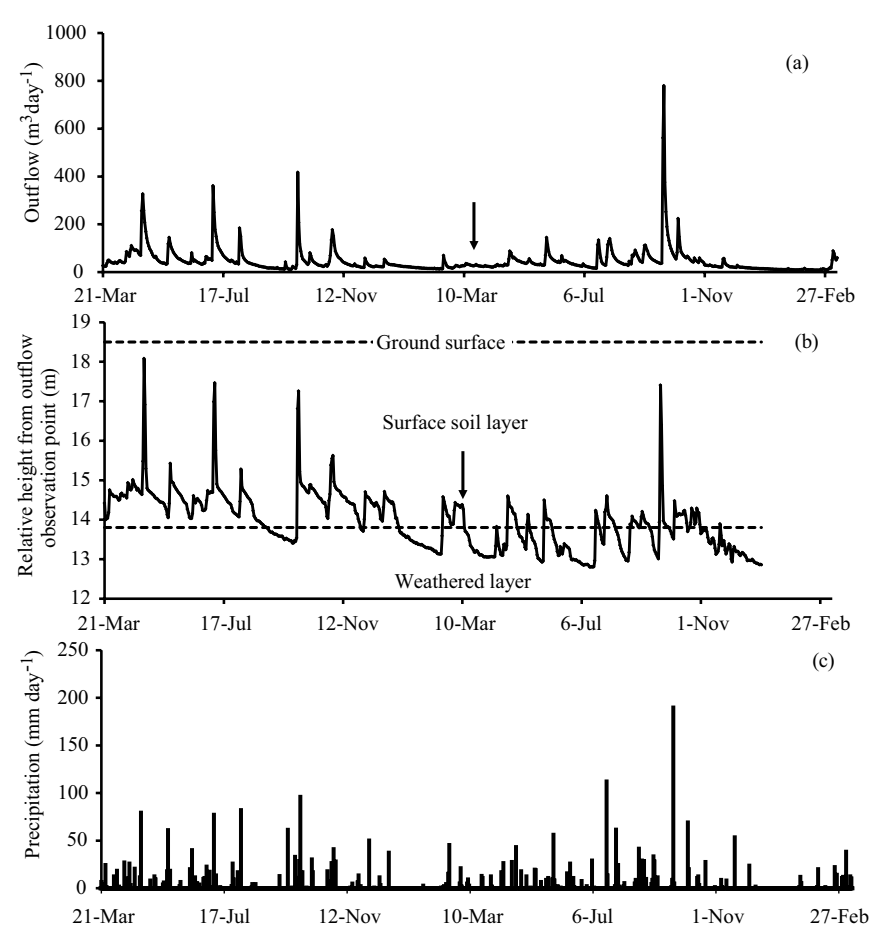

Figure 4: Observed values from 21 March 2010 to 10 March 2012 at the Katsura site:

(a)dailyoutflowatupperwatersheds,(b)groundwaterlevelinwellsatupperwatersheds and (c) daily precipitation.

\subsection{Increase in outflow and fluctuation of groundwater level at the Tsukuba site}

Figure 6 portrays the fluctuation of outflow and rainfall at BO and BB for about one year before and after 11 March 2011 when the earthquake occurred. Arrows indicate the timing of earthquake occurrence. Increase in the outflow at BO immediately after the earthquake occurrence was too small compared with increase in that by rainfall to be clearly distinguishable in this figure, although the flow increment immediately after the earthquake is distinguishable in outflow at BB.

Figure 7 depicts a magnified view of the earlier figure during 7-27 March, before and after 11 March 2011 when the earthquake occurred. The fluctuation of the outflow at BC is indicated, but it was so small compared with the resolution of sensors that the curved line indicating fluctuation is not smooth. Arrows indicate the timing of earthquake occurrence. Similarly to the Katsura site, outflow started to increase immediately after the earthquake occurrence, and recovered to outflow before the earthquake occurrence on 17 or 18 March. Sharp peaks were observed in the outflow at $\mathrm{BO}$ and $\mathrm{BC}$ at the time of outflow increase by rainfall on 7 March and 21-23 March, although no outflow increase by rainfall was observed in outflow at BB. This result agrees with arguments presented by [7] and by [8] that direct outflow was seldom included in the outflow at BB. A blunt peak was observed in outflow at all of BO, BB and $\mathrm{BC}$ immediately after the earthquake on 11 March, which resembles a pattern of increase of the flow rate by the base flow composition at the time of a rainfall. 


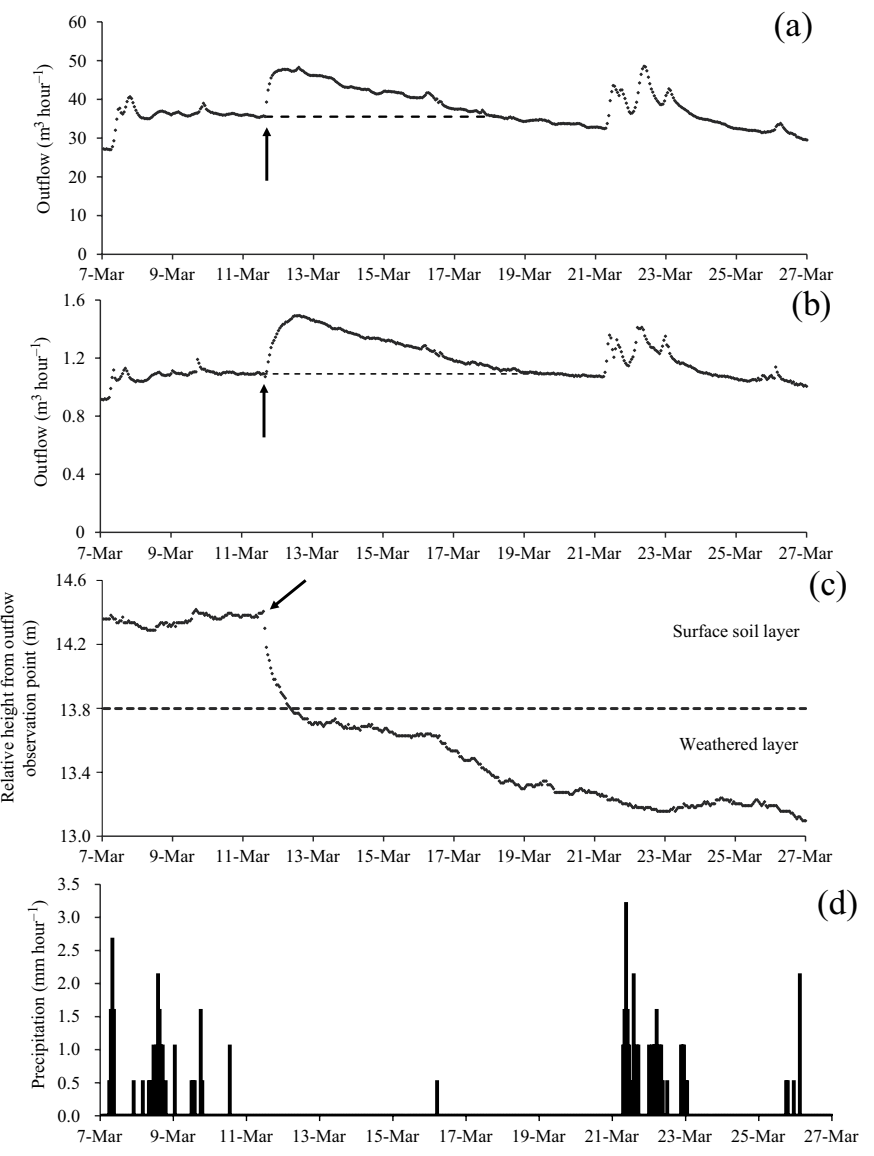

Figure 5: Observed values on 7-27 March 2011 at the Katsura site: (a) outflow of the whole watersheds, (b) outflow of upper watersheds, (c) groundwater level in wells at upper watersheds and (d) daily precipitation.

Broken lines in Figs. 7a-7c show the outflow at the earthquake occurrence. The flow increment defined by an excess outflow over this area were $66.8 \mathrm{~m}^{3}, 22.5 \mathrm{~m}^{3}$ and $29.4 \mathrm{~m}^{3}$, respectively, at $\mathrm{BO}, \mathrm{BB}$ and $\mathrm{BC}$ basins.

Figure 8 depicts the water level fluctuation in two wells (G3 and G4) on a slope above the outflow observation point at BB measured at times in January 2007-July 2012. Observations were made 19 times before and 12 times after the earthquake.

\section{RELATION BETWEEN GROUND WATER LEVEL AND OUTFLOW}

\subsection{Katsura site}

Figures 9a-9c depict the relation between observed groundwater level (h) represented by the relative height from outflow observation point at the upper watershed, and the observed daily outflow (q) on 11 March 2010 to 10 March 2011 before the earthquake, 12-20 March 2011 immediately after the earthquake and from 21 March 2011 to 31 December 2011 after the 


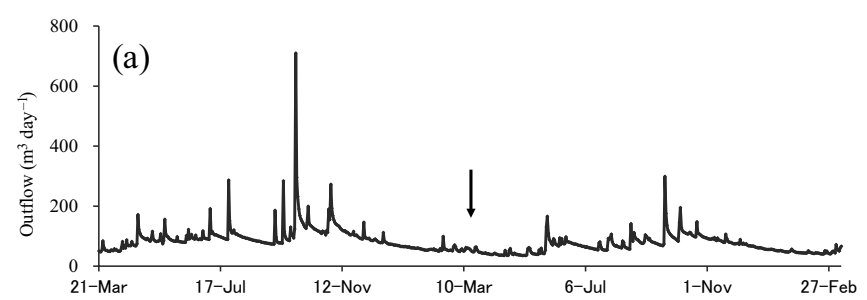

(b)
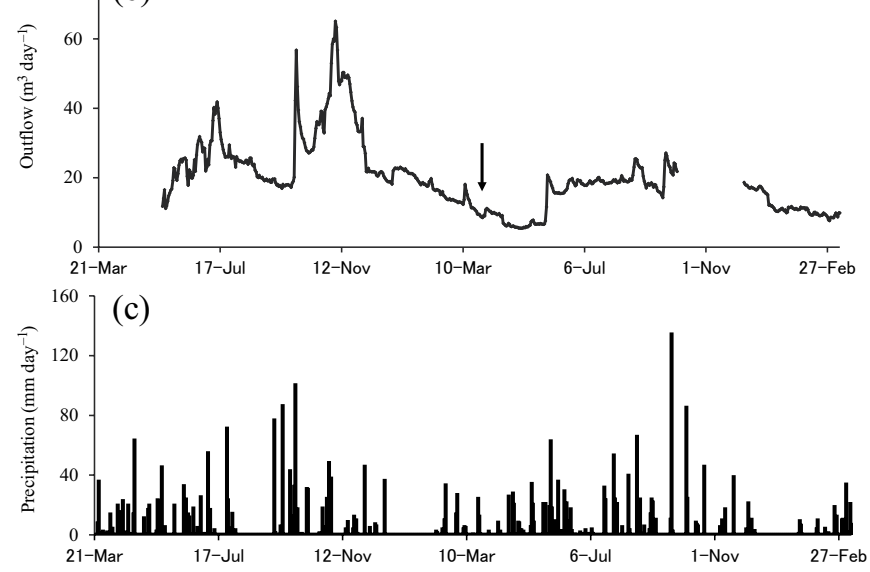

Figure 6: Observed values from 21 March 2010 to 10 March 2012 at Tsukuba site: (a) daily outflow at watershed BO, (b) daily outflow at the BB basin and (c) daily precipitation.

earthquake, respectively. Solid and broken lines presented in the figure respectively show the bottom end of data distributed areas shown in Figs. 9a and 9c connected into a straight line. The slopes of the lines are expected to represent the ease of flowing of water of underground water origin between the groundwater level observation point and the outflow observation point. The difference between these lines and each plot signifies the outflow originating in factors that are unexplainable by the groundwater level of the observation point, such as direct outflow. The gradients of the solid and broken lines in Fig. 9 are 6 and 15, respectively, and that of the latter is about 2.5 times of that of the former. It is noteworthy that data representing values immediately after the earthquake are shown in the very neighbourhood of the broken line (Fig. 9b). This result is regarded as suggesting that the earthquake encouraged underground water at the observation point to flow out easily toward the outflow observation point. No great change was observed after the earthquake in watercourses on the earth surface from before. Accordingly, as [2] pointed out, this outflow increase immediately after the earthquake is considered because the state of water of underground water origin has changed to flow easily.

Flow increment from the upper watershed was $35.9 \mathrm{~m}^{3}$ (Table 1), which is presumed to originate in underground water contained in the effective porosity of aquifers in the watershed. Decline in groundwater level in the wells was about $1 \mathrm{~m}$. An area of $359 \mathrm{~m}^{2}$ is necessary to produce a flow increment of $35.9 \mathrm{~m}^{3}$ by a decline of $1 \mathrm{~m}$ of groundwater level, for cases in which the effective porosity ratio is estimated as $10 \%$ at a lower estimate. This area is as small as about $1.5 \%$ of 2.3 ha: the area of the upper watershed. Because the effective porosity 


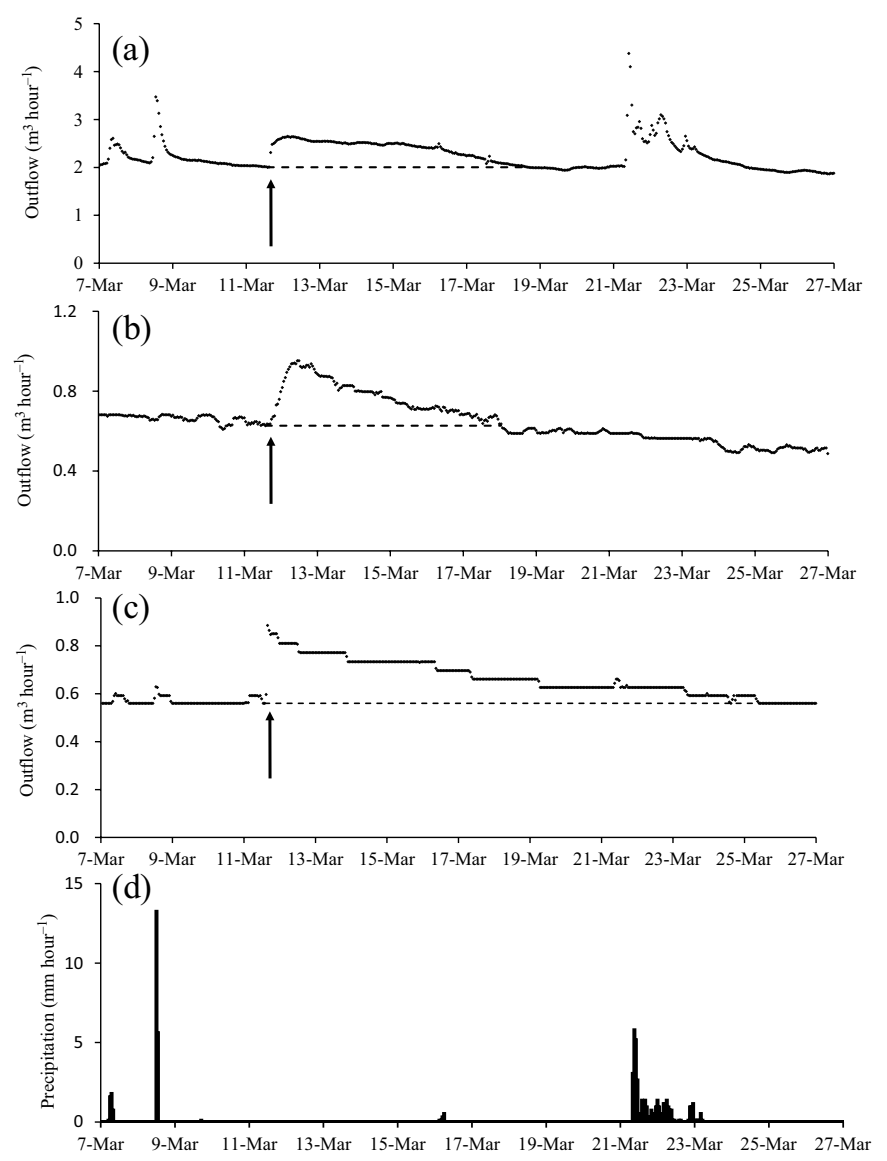

Figure 7 Observed values on 7-27 March 2011 at the Tsukuba site: (a) outflow of the whole watersheds, (b) outflow of upper watersheds, (c) groundwater level in wells at upper watersheds and (d) daily precipitation.

(a)

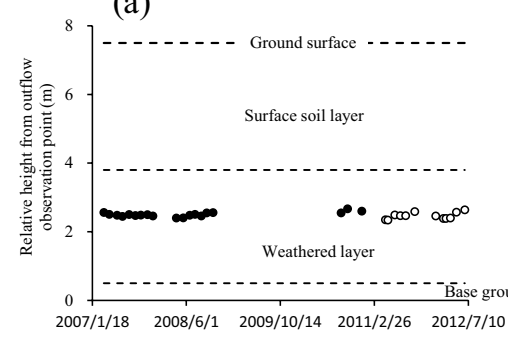

(b)

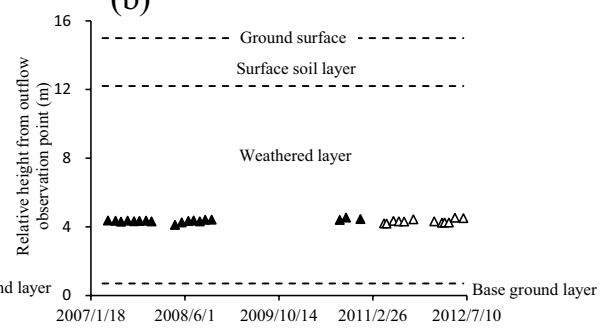

Figure 8 Observed values of groundwater level at BB basin, Tsukuba site: (a) G3; (b) G4; filled, before the earthquake; open, after the earthquake. 

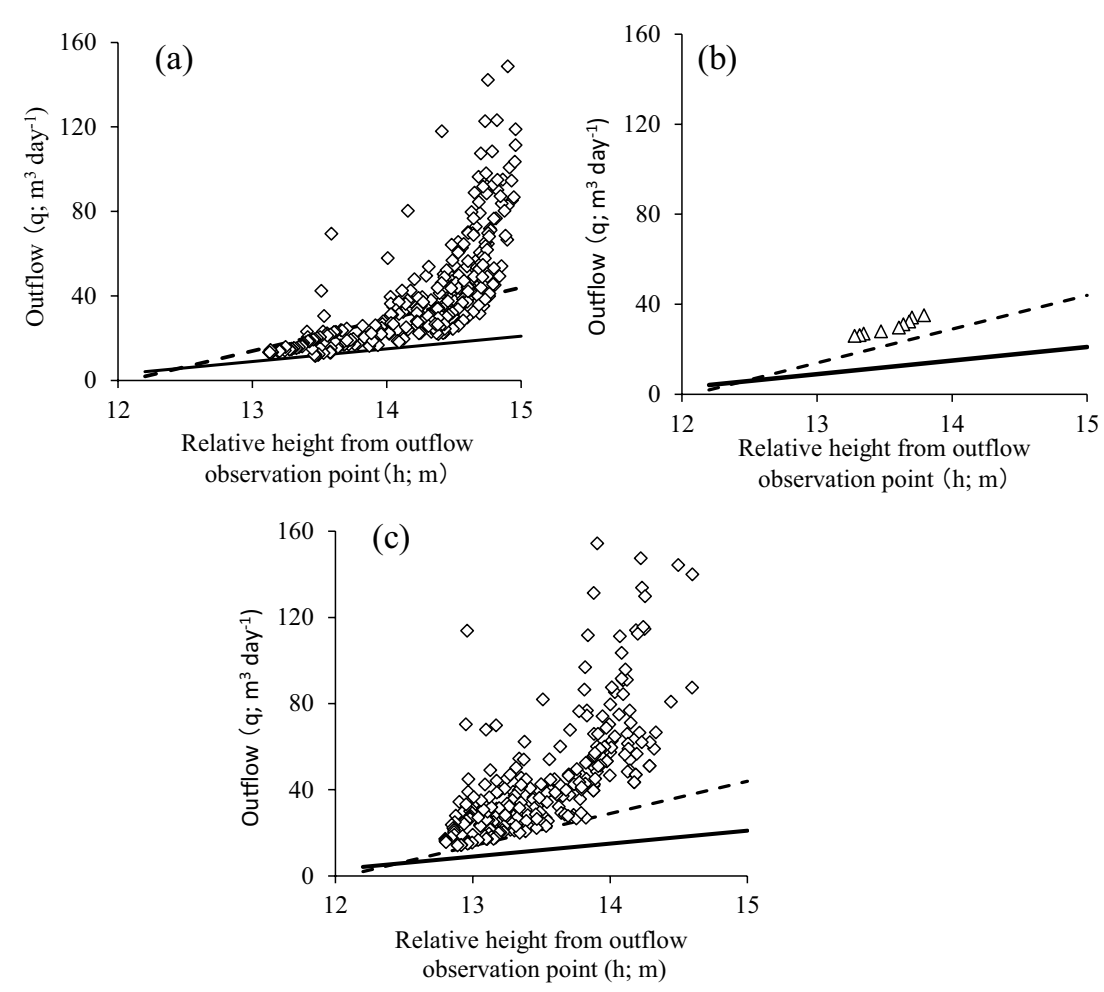

Figure 9 Relation between groundwater level and outflow at the Katsura site upper watershed (Tamai et al. [9]):

(a) before the earthquake (1 January 2010-10 March 2011);

(b) immediately after the earthquake (12-20 March 2011);

(c) after the earthquake (21 March 2011-31 December 2011); solid line, $q=6 \mathrm{~h}-69$; broken line, $q=15 \mathrm{~h}-181$.

ratio is assumed to be extremely low, the calculated necessary area is also estimated as high, but is still as small as only about $1.5 \%$. Accordingly, it is considered that the groundwater level decline of as much as $1 \mathrm{~m}$ observed at the wells occurred only in the extremely limited area of the upper watershed.

However, the equivalent rises of water in the upper and whole watersheds are almost equal (Table 1), which suggests that an increase in outflow occurred immediately after the earthquake from other small basins throughout the whole watershed.

\subsection{Tsukuba site}

Highly frequent measurement of the groundwater level at the Katsura site using a pressure water level sensor yielded results depicted in Fig. 9. The manual groundwater level observation using a measuring scale with a buzzer at the Tsukuba site does not enable us to determine the ease of flowing of water of underground water origin using a similar approach to that in Fig. 9. 

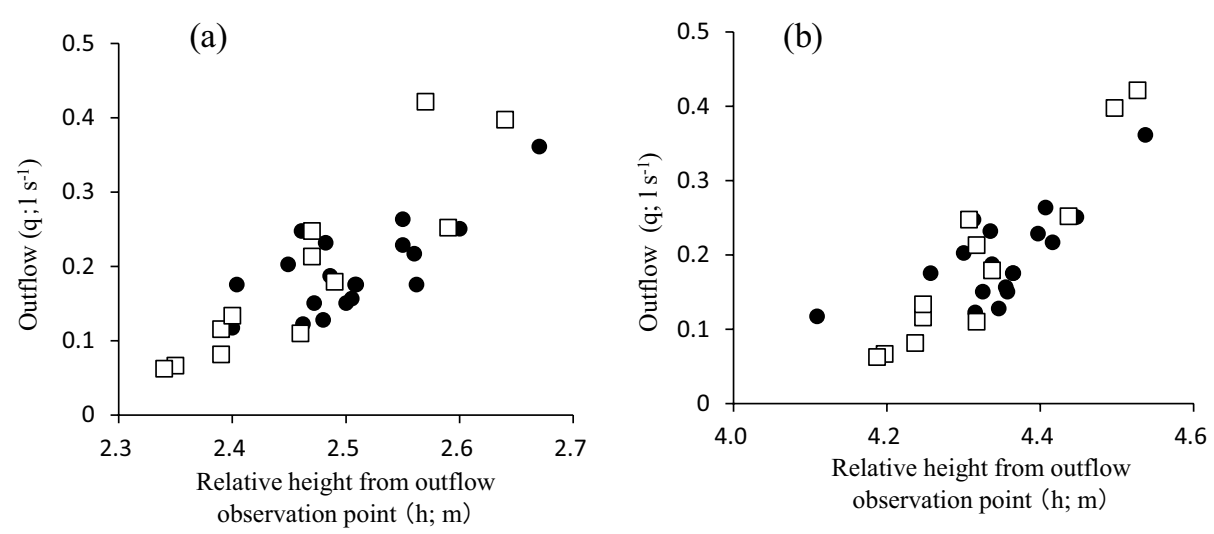

Figure 10 Relation between groundwater level and outflow in BB basin of the Tsukuba site: (a) G3, (b) G4; •, before the earthquake; $\square$, after the earthquake.

Table 1: Outflow increase in each watershed.

\begin{tabular}{llcrc}
\hline \multirow{2}{*}{ Katsura } & Upper watershed & $\begin{array}{c}\text { Increased } \\
\text { outflow }\left(\mathrm{m}^{3}\right)\end{array}$ & $\begin{array}{c}\text { Area } \\
(\mathrm{ha})\end{array}$ & $\begin{array}{c}\text { Increased } \\
\text { outflow }(\mathrm{mm})\end{array}$ \\
& Whole watershed & $1,018.9$ & 2.3 & 1.56 \\
\hline \multirow{3}{*}{ Tsukuba } & BO watershed & 66.8 & 3.9 & 1.70 \\
& BB basin & 22.5 & 0.96 & 2.30 \\
& BC basin & 29.4 & 0.63 & 4.66 \\
\hline
\end{tabular}

However, the facts that a linear relation is observed even at the time of rainfall between outflow from the BB basin and groundwater level on a slope right above BB [8] and the fact that no clear outflow peak by rainfall is recognized as an outflow characteristic from the BB basin [7] imply that almost no direct outflow composition is included in the outflow. Accordingly, Fig. 10 is prepared with groundwater level (h) represented by the relative height from outflow observation point from BB along the horizontal axis indicated in Fig. 8 and outflow (q) at BB along the vertical axis. It is considered that the points shown are depicted in the neighbourhood of a straight line equivalent to the solid line or as a broken line in Fig. 9.

Points before and after the earthquake are overlapped and distributed within the depth of the weathered layer. Consequently, it is interpreted that the relation between the outflow and groundwater level in two wells at the BB basin was unaffected by changes during or after the earthquake.

The equivalent rise of water from the BB basin was $2.30 \mathrm{~mm}$ (Table 1), about 1.3-1.5 times of that of the Katsura site. Because the area is regarded as having been adversely affected by a decline of groundwater level of about $1 \mathrm{~m}$ at the Katsura site, which is estimated as about $1.5 \%$ of the whole watershed at the lowest estimate, the local decline in the groundwater level at BB is regarded as having occurred in an extremely limited area. The two wells in the BB basin might have been located in an area with no groundwater level decline. 
Increases in outflow at $\mathrm{BO}$ and $\mathrm{BC}$ were $1.76 \mathrm{~mm}$ and $4.66 \mathrm{~mm}$, respectively, so that there was a difference of about 2.6 times, at the maximum, among the three watersheds of the Tsukuba test site.

\section{REFERENCES}

[1] Rojstaczer, S., Wolf, S. \& Michel R. Permeability enhancement in the shallow crust as a cause of earthquake-induced hydrological changes. Nature, 373, 237-239, 1995. DOI: $10.1038 / 373237 \mathrm{a} 0$.

[2] Tokunaga, T., Modeling of earthquake-induced hydrological changes and possible permeability enhancement due to the 17 January 1995 Kobe Earthquake, Japan. Journal of Hydrology, 223, 221-229, 1999. DOI: 10.1016/S0022-1694(99)00124-9.

[3] Sato, T., Sakai, R., Furuya, K. \& Kodama, T., Coseismic spring flow changes associated with the 1995 Kobe earthquake. Geophysical Research Letters, 27, 1219-1222, 2000. DOI: 10.1029/1999GL011187.

[4] Tsuboyama, Y., Tamai, K., Shimizu, T., Kubota, T., Iida, S., Nobuhiro, T. \& Sawano, S., Observation of water discharge increase from the forested catchments just after the 2011 Tohoku earthquake. Proceedings of Japan Geoscience Union 2012, U05-07, 2012.

[5] Ohnuki, Y., Yoshinaga, S., Tsuruta, T., Araki, M., Ito, E., Shichi, K., Matsuura, Y., Ono, K., Okamoto, T. \& Stewart, J.B., Distribution of soil thickness and soil physical properties in Katsura Headwater Catchment. Bulletin of Forestry and Forest Products Research Institute, 13, 43-59, 2014 (in Japanese with English summary).

[6] Ohnuki, Y., Yoshinaga, S. \& Noguchi, S. Distribution and physical properties of colluvium and saprolite in unchannelized valleys in Tsukuba Experimental Basin, Japan, Journal of Forest Research, 4, 207-215, 1999. DOI: 10.2136/sssaj1991.03615995005500040006x

[7] Kabeya, N., Shimizu, A., Nobuhiri, T., Zhang, J., Tsuboyama, Y., Runoff characteristics from forested small basins with thick weathered layer (1) - Observations of outflow from springs. Transactions of Japanese Forestry Society, 115, 806, 2004 (in Japanese).

[8] Noguchi, S., Kishioka, T. \& Kikuya, A. Runoff characteristics of springs in Tsukuba Forest Experimental Watershed. Transactions of Japanese Forestry Society, 101, 605-607, 1990 (in Japanese).

[9] Tamai, K., Sawano, S., Shimizu, T., Kobayashi, M., Iida, S., Shinomiya, Y. \& Kabeya, N., Changes of 'GWL-Q' relation caused by the great East Japan earthquake - Comparison of two small mountainous catchments in Ibaraki Pref. Transactions of Japanese Association of Hydrological Sciences, 45-48, 2015 (in Japanese). 